\title{
Differences in genetic diversity and divergence between brooding and broadcast spawning corals across two spatial scales in the Coral Triangle region
}

\author{
Rosa Maria van der Ven ${ }^{1,2}$ [ Hanneloor Heynderickx ${ }^{1,3} \cdot$ Marc Kochzius $^{1}$
}

Received: 7 May 2020 / Accepted: 3 December 2020

( ) The Author(s) 2021, corrected publication 2021

\begin{abstract}
The Coral Triangle region contains the world's highest marine biodiversity, however, these reefs are also the most threatened by global and local threats. A main limitation that prevents the implementation of adequate conservation measures is that connectivity and genetic structure of populations is poorly known. The aim of this study was to investigate the genetic diversity, population structure and connectivity patterns of tropical corals in Indonesia on two different spatial scales, as well as by comparing two different reproduction strategies. Genotyping was based on microsatellite markers for 316 individual Seriatopora hystrix colonies and 142 Acropora millepora colonies sampled in Pulau Seribu and Spermonde Archipelago in 2012 and 2013. Differences in allelic diversity and a strong signature of divergence associated with historical land barriers at the Sunda Shelf were found for the brooding coral Seriatopora hystrix. However, differences in diversity and divergence were not pronounced in the broadcast spawning coral Acropora millepora. Within Spermonde Archipelago, two groups were identified: (1) sites of the sheltered inner-shelf and mid-shelf, which were found to be highly interconnected and (2) mid-shelf and outer-shelf sites characterised by higher differentiation. These patterns of contemporary dispersal barriers and genetic diversity can be explained by the differences in life history of the corals, as well as by oceanographic conditions facilitating larval dispersal. The contemporary dispersal barriers found within the Spermonde Archipelago emphasise the need for incorporating connectivity data in future conservation efforts.
\end{abstract}

\section{Introduction}

The Coral Triangle region encloses more than $86,500 \mathrm{~km}^{2}$ of coral reef area (35\% of all global coral reefs) and includes the exclusive economic zones of eight countries (Indonesia,

Responsible Editor: C. Voolstra.

Reviewed by E. D. Crandall and an undisclosed expert.

Supplementary Information The online version contains supplementary material available at https://doi.org/10.1007/ s00227-020-03813-8.

Rosa Maria van der Ven

Rosa.vanderven@wur.nl

1 Marine Biology, Ecology and Biodiversity, Vrije Universiteit Brussel, (VUB), Brussels, Belgium

2 Marine Animal Ecology Group, Wageningen University, Wageningen, The Netherlands

3 Department of Botany, University of Otago, Dunedin 9054, New Zealand
Malaysia, The Philippines, Papua New Guinea, Timor-Leste, Solomon Islands, Brunei Darussalam and Singapore; Burke et al. 2012). The world's highest marine biodiversity is found within this region, accounting for $>76 \%$ of coral species and more than 3000 fish species (Allen and Werner 2002; Allen 2008; Veron and Smith 2009; Burke et al. 2012). The marine resources of this region's coral reefs benefit over 120 million people by providing goods and services, such as fisheries resources, shoreline protection and attraction for tourism (Burke et al. 2011, 2012; Foale et al. 2013). However, coral reefs of this region are threatened by global stressors, such as climate change and subsequent extreme weather events, as well as by local anthropogenic threats, such as overfishing and destructive fishing, watershed pollution, and reef removal for coastal development (Burke et al. 2011, 2012; Hoegh-Guldberg et al. 2017). Currently, more than $85 \%$ of the reefs within the Coral Triangle region are at risk of disappearing (Burke et al. 2012). In response, a multilateral partnership of the above-mentioned countries, the Coral Triangle Initiative on Coral Reefs, Fisheries and Food Security (CTI-CFF), also shortly known as the Coral 
Triangle Initiative (CTI), aims to set up sustainable networks of Marine Protected Area's (MPAs). Only 16\% of reefs within the Coral Triangle currently fall under MPA protection, and management is generally poor or lacking, with just $1 \%$ rated as effectively managed (Burke et al. 2012). MPAs can support coral reef conservation by maximising reef resilience to environmental changes, but to achieve this, knowledge on connectivity of reefs should be incorporated in MPA design and management (Almany et al. 2009; Bellwood et al. 2004; Green et al. 2014).

The reefs of Pulau Seribu and Spermonde Archipelago in Indonesia offer a unique opportunity to study the connectivity of coral reefs under variable environmental conditions. Both Pulau Seribu and Spermonde Archipelago experience an in- to offshore gradient of anthropogenic stressors related to pollution from the nearby cities, Jakarta and Makassar, respectively.

Pulau Seribu or "Thousand Islands" is a reef complex that consists of 105 islands in front of Jakarta on Java and extends $80 \mathrm{~km}$ northwest into the Java Sea (see Figs. 1 and 2a). The Spermonde Archipelago is situated off Southwest Sulawesi, in the southern Makassar Strait, featuring 100 coral-fringed small islands across a 40-km-wide carbonate shelf, with depth ranging from 10 to more than $50 \mathrm{~m}$ [see
Fig. 2b and Cleary et al. (2005)]. Reoccurring events of sea level decrease during the glaciations in the Pliocene and Pleistocene exposed reefs in Pulau Seribu and Spermonde Archipelago and created isolated ocean basins on either side (Voris 2000; light-grey area in Fig. 1). Subsequent recolonisation probably occurred from different source populations, a hypothesis confirmed by genetic studies in giant clams (Kochzius and Nuryanto 2008). Both Pulau Seribu and Spermonde Archipelago can be divided into inshore, midshore and offshore zones that differ in oceanography, geomorphology and diversity, as well as in the level of exposure to an in- to offshore gradient of anthropogenic stressors related to run-off and pollution from the nearby cities, Jakarta and Makassar, respectively (Edinger et al. 1998; Cleary et al. 2005; Cleary and Suharsono 2006; Polonia et al. 2015). Within the Indo-Malay Archipelago, the main current is the Indonesian Throughflow (ITF), which originates from the northern tropical Pacific and flows from north to south yearround (Fig. 1; Gordon 2005). The ITF connects the Pacific and Indian Ocean through Makassar Strait, facilitating connectivity of populations in the Sulawesi Sea, Makassar Strait and the Flores Sea (Kochzius and Nuryanto 2008; Timm and Kochzius 2008). In addition to the prevailing ITF, monsoons create seasonal wind shifts accompanied by changes

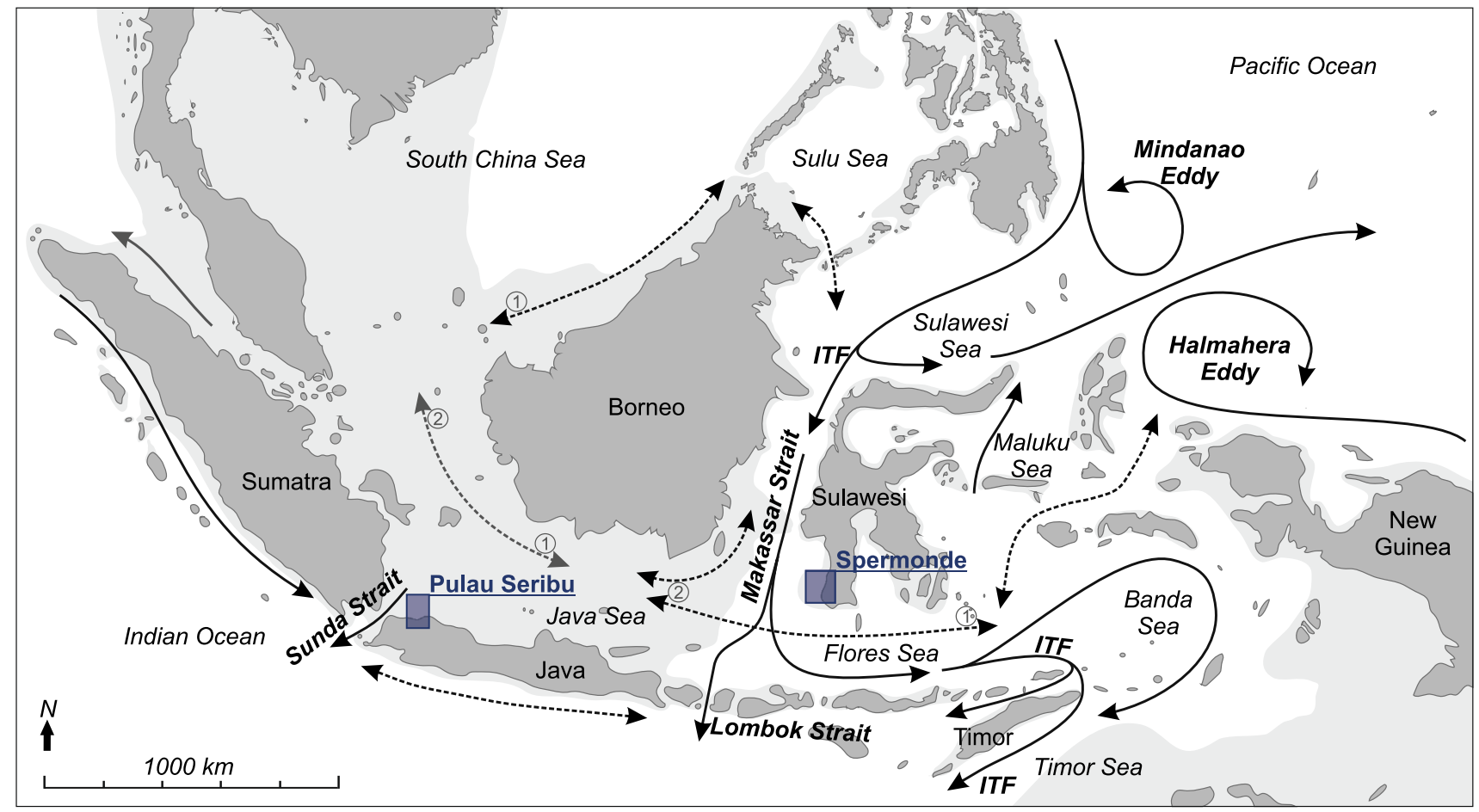

Fig. 1 Map of the Indo-Malay Archipelago with major ocean currents indicated schematically; solid arrows are permanent currents; dashed lines are currents changing with monsoon seasons (Edinger et al. 2002; Wyrtki 1961; Gordon 2005); ITF: Indonesian Throughflow; (1) dominant current direction during the southwest monsoon (Novem-
ber-February); (2) dominant current direction in the northeast monsoon (May-August). Light-grey area indicates the Pleistocene maximum sea level low stand of $120 \mathrm{~m}$ (Voris 2000); squares indicate the sample sites 


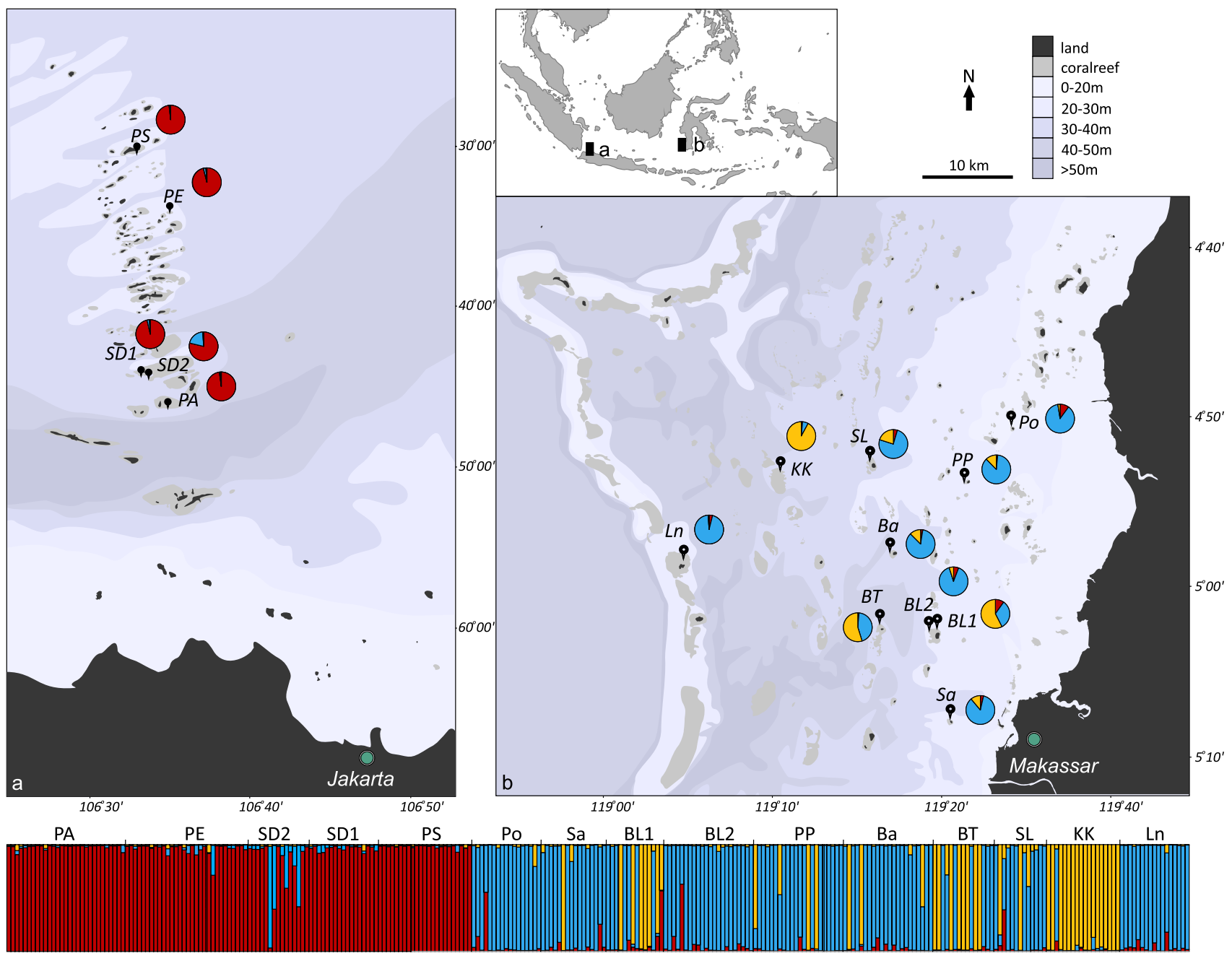

Fig. 2 Map showing sample sites of Seriatopora hystrix in two locations in Indonesia: a Pulau Seribu, and b Spermonde Archipelago. The pie charts show the distribution of three genetic clusters $(K=3)$ identified by the Bayesian clustering implemented in STRUCTURE 2.3.4 (Pritchard et al. 2000) based on seven microsatellite loci and

in current direction in the Java and Flores Seas (Fig. 1), with the dominant inflow in the Java Sea from the South China Sea during the southwest monsoon (November-February) and from the Makassar strait during the northeast monsoon (May-August; Gordon 2005; Edinger et al. 2002).

The stony coral Seriatopora hystrix (Pocilloporidae; Dana 1846) is common on shallow reefs and intertidal reef flats and has a widespread distribution in the Indo-Pacific (Veron 2000). Seriatopora hystrix is a brooding coral that releases planula larvae with a short pelagic larval duration (PLD) year-round in the tropics (summarised in Prasetia et al. 2017). Most settlement (50\%) occurs within $6 \mathrm{~h}$ after release, although the PLD can reach up to 1 week (Baird 2001). Seriatopora hystrix larvae were shown to settle close to their natal colony in northern Western Australia analysed for all sample sites combined. c The colours in the bar plot visualise the individual's estimated membership fraction in each of the three clusters, with each vertical bar representing one individual. Sample site codes see Table 1 and ESM Appendix S1

(Underwood et al. 2007), however, longer dispersal distances have occurred (van Oppen et al. 2008).

Acropora millepora (Acroporidae; Ehrenberg, 1834) also has a widespread distribution in the Indo-Pacific and is a common inhabitant of shallow reef flats, lagoons and upper reef slopes (Veron 2000). It is a broadcast spawning coral and releases buoyant gamete bundles with eggs and sperm into the water column in multispecies spawning events. Within the Java Sea, acroporids were found to have two spawning periods per year: in spring (March and April) and in autumn (September-October), coinciding with the transition periods between monsoons (Permata et al. 2012; Wijayanti et al. 2019). Limited data are available for spawning in Spermonde Archipelago, but an early spring and autumn spawning are highly likely, as within the 
whole Coral Triangle region. Acroporid's spawning events take place between March and May and between September and December (reviewed in Keith et al. 2016). Acropora millepora has a long PLD of 60 days in laboratory studies, but a longer PLD can be expected based on studies of other acroporids (Graham et al. 2008). Although there was an indication for A. millepora larvae settling on their natal reefs in the Great Barrier Reef (GBR), simultaneous long-distance dispersal was found over $>1000 \mathrm{~km}$ (van Oppen et al. 2011).

While self-fertilisation in hermaphrodite broadcast spawning corals is mostly or completely restricted, brooding corals often have the potential for self-fertilisation (selfing), yet these rates are variable (reviewed in Carlon 1999). Additionally, brooded larvae often have limited dispersal capacity, which increases the likelihood of outcrossing with related individuals. These contrasting life history characteristics make S. hystrix and A. millepora interesting models for studying coral genetic connectivity in this area.

In this study, the genetic diversity, population structure and connectivity patterns of tropical corals in Indonesia were investigated on two different scales, as well as by comparing two different reproduction strategies of the brooding coral $S$. hystrix and the broadcast spawning coral A. millepora. The three hypotheses we aimed to test were: (1) there is genetic structure resulting from historical land barriers to larval dispersal and subsequent recolonisation of Pulau Seribu and Spermonde Archipelago from different ocean basin populations; reef distance to shore influences the population genetic structure within (2) Pulau Seribu; and within (3) Spermonde Archipelago. These three hypotheses were tested using ten microsatellite markers for S. hystrix and seven for A. millepora.

\section{Materials and methods}

\section{Sampling, DNA extraction and microsatellite genotyping}

Coral samples of $S$. hystrix and A. millepora were collected during two expeditions between September 2012 and March 2013 as part of the of the SPICE III program (Science for the Protection of Indonesian Coastal Marine Ecosystems). Species identity was assessed through visual inspection of the main morphological characters of the coral species. Species identity was re-confirmed before DNA extraction. In total, 316 individual $S$. hystrix colonies were sampled at 5 locations in Pulau Seribu and 10 locations in Spermonde Archipelago, and 142 individual A. millepora colonies were sampled at 2 locations in Pulau Seribu and 6 locations in Spermonde Archipelago (Figs. 1, 2, 3, ESM Appendix S1 and CITES permits 2013BE776/PE, 3260/
IV/SATS-LN/2013). To reduce the chance of sampling the same colony twice, colonies were selected with a distance of at least $2 \mathrm{~m}$ between consecutive collections. DNA was extracted with the Omega Bio-tek ${ }^{\circledR}$ E.Z.N.A. ${ }^{\circledR}$ Tissue DNA kit (Norcross, GA, USA) following the manufacturer's animal tissue protocol. The purity and concentration of the DNA extract was determined with a NanoDrop 2000 spectrophotometer (Thermo-scientific, Waltham, Ma, US). Samples of S. hystrix and A. millepora were genotyped with, respectively, ten or seven microsatellite primer pairs (details of primers, PCR conditions and scoring are given in ESM Appendix S2 and S3).

\section{Genetic diversity analysis}

Identical multilocus genotypes (MLGs) that were likely to be the result of fragmentation of the coral colony were identified with the software GenAlEx 6.503 (Peakall and Smouse 2012). The departure from Hardy-Weinberg equilibrium (HWE) was determined for each locus using FSTAT 2.9.3 (Goudet 1995) and presented as $F_{\text {IS }}$ (calculated as smallF (Weir and Cockerham 1984)), with significance levels based on 105,000 permutations for $S$. hystrix and 56,000 for $A$. millepora. In all FSTAT analyses, the number of permutations was automatically determined based on the number of loci and populations in the experimental design. MicroChecker 2.2.3 (van Oosterhout et al. 2004) was used to check for microsatellite null alleles and scoring errors. Populations with heterozygote deficiency were further analysed with INEst 2.0 (Chybicki and Burczyk 2009), which utilises a Bayesian approach estimating both null alleles and inbreeding simultaneously (Campagne et al. 2012). The Markov chain Monte Carlo (MCMC) was run with 50,000 generations for burn-in followed by 500,000 additional cycles. RMES software (David et al. 2007) was used to estimate mean population self-fertilisation (selfing) rates $(S)$ based on 100,000 iterations. Linkage disequilibrium (LD) values for $S$. hystrix and A. millepora were calculated using FSTAT and the $p$ values for genotypic disequilibrium were based on 31,500 and 16,800 permutations, respectively. The number of alleles per population, corrected for sample size and expressed as allelic richness (Ar), was also calculated using FSTAT, whereas the observed, expected and unbiased heterozygosity (corrected for sample size) and private alleles were calculated using GenAlEx. Lastly, a one-sided comparison (9999 permutations) of the allelic richness $A_{\mathrm{r}}$ was performed using FSTAT to compare the in- to offshore zones within and between Pulau Seribu and Spermonde Archipelago. 


\section{Population structure}

Bayesian clustering based on the Markov chain Monte Carlo (MCMC) assignment method was run without prior population information and under the admixture model to determine the number of genetic clusters $(\mathrm{K})$ in the software STRUCTURE 2.3.4 (Pritchard et al. 2000) with the ParallelStructure package (Besnier and Glover 2013) in R version 3.6.3 (https://www.r-project.org/) on the CIPRES Science Gateway portal (Miller et al. 2015). Analyses included 10 runs with a burn-in length of 100,000 and 1,000,000 MCMC replications. HARVESTER 0.6.94 (Earl and Vonholdt 2012) was used to visualise and analyse the STRUCTURE output by plotting log probability L (K) and $\Delta \mathrm{K}$ (Evanno et al. 2005). A hierarchical Analysis of Molecular Variance (AMOVA) (Excoffier et al. 1992) was conducted with GenAlEx, to assess the geographical structuring of genetic variation. Groupings were based on historical land barriers and different sources of recolonisation after the rise of sea level (Pulau Seribu versus Spermonde Archipelago), and designated shelf-zones within Pulau Seribu and Spermonde Archipelago. Significance was tested with 9999 permutations.

To investigate genetic structuring among populations complementary measures of differentiation were included $\left(F_{\mathrm{ST},} \mathrm{D}_{\mathrm{EST}}\right.$ and $\left.R_{\mathrm{ST}}\right)$. Pairwise $F_{\mathrm{ST}}$ values were estimated using the method of Weir and Cockerham (1984) $(\theta)$ in FSTAT and tested for significance with 105,000 and 56,000 permutations for S. hystrix and A. millepora, respectively. Statistical significance for all pairwise tests was adjusted for multiple comparisons by a Holm-Bonferroni correction (Holm 1979). Using GenAlEx, $\mathrm{D}_{\mathrm{EST}}$ (Jost 2008) was calculated as an additional measure of allelic differentiation as it forms a better estimator when diversity is high, and was tested for significance with 9.999 permutations. Pairwise $R_{\mathrm{ST}}$ values (Slatkin 1995) were calculated in GenAlEx and the level of significance was tested with 9999 permutations. As recommended in, e.g. Jost et al. (2018) and Meirmans and Hedrick (2011), the results of $F_{\mathrm{ST}} \mathrm{D}_{\mathrm{EST}}$ and $R_{\mathrm{ST}}$ were compared to gain insights into the main causes of the population differentiation. SPAGeDi (Hardy and Vekemans 2002) was used to test if stepwise mutations added to differentiation $\left(R_{\mathrm{ST}}>F_{\mathrm{ST}}\right)$, in which case $R_{\mathrm{ST}}$ (Slatkin 1995) would reflect population differentiation better than $F_{\mathrm{ST}}$. Additionally, the relative contribution of mutation versus migration to population differentiation over distance intervals was investigated using 20,000 permutations. A significant $R_{\mathrm{ST}}$ value would emphasise the role of mutation relative to migration rate in the differentiation of distant populations. Pairwise $F_{\mathrm{ST}^{-}} \mathrm{D}_{\mathrm{EST}^{-}}$and $R_{\mathrm{ST}}$ values were used in a Mantel test of isolation-by-distance (IBD), with and without transformations as suggested by
Rousset (1997), and tested with 9999 permutations in GenAlEx.

\section{Results}

\section{Null alleles and genotypic diversity}

Of the ten microsatellite markers used for S. hystrix, three markers were eliminated from the analysis (Sh2-002, Sh3007, Sh3-008) as they did not amplify in samples from several sites and showed high prevalence of null alleles in Micro-Checker and INEst (ESM Appendix S4). Of the 316 sampled colonies of S. hystrix, 290 were found to contain unique multilocus genotypes (MLGs). Pairs of identical MLGs were found at nine sampling sites: one pair in PA, four pairs in PE, one pair in SD1, five pairs and one triplet in PS, two pairs in Sa, two pairs and one triplet in BL1, one pair in BT, two pairs and one triplet in KK and two pairs in Ln. Clonal richness (R) indicated low contribution of asexual reproduction at these sample sites, although the sampling design (sampling colonies with at least $2 \mathrm{~m}$ distance) could have resulted in an underestimation of this contribution (Table 1).

All seven microsatellite markers for A. millepora were amplified in all the samples. Of the 142 sampled colonies, 136 were found to contain unique multilocus genotypes (MLGs). Pairs of identical MLGs were found at three sampling sites: two pairs in PA, one pair in PS and one quadruplet in KK. The clonal richness indicated a low contribution of asexual reproduction (Table 1).

As the probability of identity (PI) was low $(<0.005$ for all sample sites in $S$. hystrix, and $<0.0001$ for all sample sites in A. millepora, well below the 0.01 set for adequate population studies; (Waits et al. 2001)), the chance of colonies sharing the same genotype coincidentally was very low. Therefore, the colonies sharing identical MLGs were considered as potentially belonging to the same individual, most likely as the result of the coral colony fragmentation. Further analyses were performed with a reduced dataset, with all but one of the duplicated MLGs removed.

\section{Genetic diversity}

The 7 remaining microsatellite loci in $S$. hystrix were polymorphic for all 15 sample sites, with 2-9 alleles per locus, except for locus Sh3-003, which was monomorphic for 3 sites (ESM Appendix S5). All sample sites showed positive $F_{\text {IS }}$ values, of which most with significant departures from HWE, indicating heterozygotic deficits (Table 1). Selfing rates $(S)$ ranged from 0 to 0.467 in Pulau Seribu and from 0 to 0.41 in Spermonde Archipelago (Table 1). 
Linkage Disequilibrium was not detected in any of the sites $(p<0.01$; data not shown). Private alleles were found more frequently and in higher numbers in sites in Spermonde Archipelago, with a maximum of nine private alleles in KK (Table 1). The allelic richness $\left(A_{\mathrm{r}}\right)$ ranged from 2.5 to 2.9 in Pulau Seribu and from 3.5 to 4.6 in Spermonde Archipelago, the observed heterozygosity $\left(H_{\mathrm{O}}\right)$ from 0.238 to 0.330 in Pulau Seribu and from 0.381 to 0.604 in Spermonde Archipelago, and the unbiased expected heterozygosity $\left(\mathrm{u} H_{\mathrm{E}}\right.$ ) from 0.353 to 0.409 in Pulau Seribu and from 0.488 to 0.678 (Table 1). The one-sided comparisons for S. hystrix of $A_{\mathrm{r}}$ and $H_{\mathrm{O}}$ in Pulau Seribu and Spermonde Archipelago showed significantly higher $A_{\mathrm{r}}$ and $H_{\mathrm{O}}$ within Spermonde Archipelago, with $A_{\mathrm{r}}=4.07, H_{\mathrm{O}}=0.479$ and $A_{\mathrm{r}}=2.65, H_{\mathrm{O}}=0.295$, respectively (Pulau Seribu $<$ Spermonde Archipelago $p<0.001$ ). No differences in genetic diversity were found within the in- to offshore gradient in Pulau Seribu and Spermonde Archipelago $(p>0.05)$.

The 7 microsatellite loci in A. millepora were polymorphic for all 8 sample sites, with 3-17 alleles per locus, except for locus Amil2_006, which was monomorphic for 3 sites (ESM Appendix S6). All sample sites showed positive $F_{\text {IS }}$ values ranging between 0.268 and 0.399 , all with significant departures from HWE $(p<0.05$, Table 1$)$. Upward bias of $F_{\text {IS }}$ values can be caused by genotyping errors, unaccounted population structure such as Wahlund effect, and the effect of population selfing or inbreeding. Analysis with INEst indicated that inbreeding, rather than null alleles, was causing the high $F_{\text {IS }}$ values in all sample sites (ESM Appendix S7). There was a low contribution of selfing, with rates ranging from 0 to 0.05 in Pulau Seribu and 0-0.06 in Spermonde Archipelago (Table 1). Linkage Disequilibrium was not detected at any of the sites ( $p<0.01$; data not shown). Private alleles were found in all sites except Po and KK, with a maximum of six in $\mathrm{Sa}$ (Table 1). The allelic richness $\left(A_{\mathrm{r}}\right)$ was 4.1 and 3.6 in Pulau Seribu and ranged from 3.6 to 4.3 in Spermonde Archipelago, the observed heterozygosity $\left(H_{\mathrm{O}}\right)$ was 0.403 and 0.392 in Pulau Seribu and ranged from 0.360 to 0.435 in Spermonde Archipelago, and the unbiased expected heterozygosity $\left(\mathrm{u} H_{\mathrm{E}}\right)$ was 0.594 and 0.542 in Pulau Seribu and ranged from 0.486 to 0.656 in Spermonde Archipelago (Table 1). No differences in genetic diversity were found between and within Pulau Seribu and Spermonde Archipelago $(p>0.05)$.

\section{Population structure}

\section{Seriatopora hystrix}

In S. hystrix, significant differentiation was found in $92 \%$ of the pairwise population comparisons based on $F_{\mathrm{ST}}$, and $98 \%$ of the pairwise population comparisons based on $\mathrm{D}_{\mathrm{EST}}$ (ESM Appendix S8). The highest genetic differentiation was found comparing Pulau Seribu and Spermonde Archipelago, with $F_{\mathrm{ST}}$ values ranging from 0.141 to 0.398 and $\mathrm{D}_{\mathrm{EST}}$ values ranging from 0.164 to 0.503 . Moderate to high differentiation was observed within Spermonde Archipelago ( $\left.F_{\mathrm{ST}}: 0.011-0.348 ; \mathrm{D}_{\mathrm{EST}}: 0.023-0.546\right)$, but lower differentiation within Pulau Seribu $\left(F_{\mathrm{ST}}: 0.012-0.243\right.$; $\mathrm{D}_{\mathrm{EST}}$ : 0.007-0.189). The contribution of stepwise mutations $\left(R_{S T}>F_{\mathrm{ST}}\right)$ was tested with a one-sided permutation test and significant $(p<0.05)$ contributions of stepwise mutations in allele sizes were detected for all loci in S. hystrix, but when inspecting and compiling distance intervals, significant values were mostly found within Spermonde Archipelago, while $F_{\mathrm{ST}}$ is a better indicator within Pulau Seribu (ESM Appendix S9). Due to this, and because such permutation tests were shown to be unreliable for loci with lower polymorphism (Hardy et al. 2003) as found in S. hystrix (ESM Appendix S5), all three estimators $\left(F_{\mathrm{ST}}, \mathrm{D}_{\mathrm{EST},} R_{\mathrm{ST}}\right)$ were included and compared in the subsequent analyses. Pairwise $R_{\mathrm{ST}}$ (ESM Appendix S10) confirms the moderate to high differentiation observed within Spermonde Archipelago $\left(R_{\mathrm{ST}}: 0.000-0.555\right)$, as well as the lower differentiation within Pulau Seribu ( $\left.R_{\mathrm{ST}}: 0.000-0.292\right)$. $\mathrm{D}_{\mathrm{EST}}$ was congruent with $F_{\mathrm{ST}}$ values within Pulau Seribu. However, consistently higher values of $\mathrm{D}_{\mathrm{EST}}$ and $R_{\mathrm{ST}}$ were observed in Spermonde Archipelago, indicating low migration rates relative to mutation rates in these sample sites, and possibly the underestimation of $F_{\mathrm{ST}}$, especially in KK and Ln. A Mantel test indicated no significant correlation between population differentiation (for $F_{\mathrm{ST}}, \mathrm{D}_{\mathrm{EST}}$ or $R_{\mathrm{ST}}$ ) and geographic distance within Pulau Seribu or Spermonde Archipelago ( $p>0.05$, data not shown). But significant correlation between Pulau Seribu and Spermonde Archipelago was found based on $F_{\mathrm{ST}}$ and $\mathrm{D}_{\mathrm{EST}}(p<0.05$, ESM Appendix S11, based on transformed $\left.F_{\mathrm{ST}}\right)$.

STRUCTURE analysis (ESM Appendix S12) suggested $K=3$ as the most likely number of genetic clusters for all sampling sites (Fig. 2a-c). Based on the proportion of each genetic cluster within each sample site, a clear distinction of (1) Pulau Seribu and (2) Spermonde Archipelago, both forming a mixed group of two genetic clusters, was found. When analysed separately, Pulau Seribu showed no unambiguous number of clusters in STRUCTURE other than $K=2$, in which all sites show mixed signatures (ESM Appendix S12). Within Spermonde Archipelago, two clusters $(K=2)$ were found in STRUCTURE, similar to analyses including all sample sites (ESM Appendix S13). Based on the proportion of each genetic cluster within each sample site, two groups were defined within Spermonde Archipelago (1) BL1, BT, and KK, and (2) BL2, Ln, Po, Sa, PP, Ba, and SL.

In the PCoA including all data, the first axis divides Pulau Seribu from Spermonde, explaining 17\% of the variation (Fig. 4a). In the PCoA based on pairwise $F_{\mathrm{ST}}$ of sample sites in Pulau Seribu, the first axis divides SD2 and SD1 from PA, 
PE, PS, and the second axis separates PA and PS from this segregation, as well as SD1 from SD2, together explaining $91 \%$ of the variation (Fig. 4b). In the PCoA including only sites in Spermonde Archipelago, the first axis divides BL1, BT and KK from all others. The second axis separates BL1 from this segregation, as well as BL2, Ba, SL and Ln, from Po, Sa and PP, together explaining $67 \%$ of the variation (Fig. 4c).

The hierarchical AMOVA revealed that $13 \%$ genetic variation was found between the clusters within the Java Sea ( $p<0.001$; ESM Appendix S14). Grouping based on zones in Pulau Seribu gave a lower component of variance $(2 \%$ $(p<0.001)$, while no significant grouping was found in Spermonde Archipelago $(p>0.05)$.

\section{Acropora millepora}

For A. millepora, significant differentiation was found in $17 \%$ of the pairwise population comparisons based on $F_{\mathrm{ST}}$, and $79 \%$ of the pairwise population comparisons based on $\mathrm{D}_{\mathrm{EST}}$ (ESM Appendix S15). Most significant comparisons were found between Pulau Seribu and Spermonde Archipelago, with $F_{\mathrm{ST}}$ values ranging from 0.009 to 0.135 and $\mathrm{D}_{\mathrm{EST}}$ values ranging from 0.034 to 0.274 . A lower differentiation was found within Spermonde Archipelago $\left(F_{\mathrm{ST}}\right.$ : 0.000-0.118; $\left.\mathrm{D}_{\mathrm{EST}}: 0.012-0.240\right)$ and no differentiation between the two sites within Pulau Seribu $\left(F_{\mathrm{ST}}=0 ; \mathrm{D}_{\mathrm{EST}}=0\right)$. The contribution of stepwise mutations $\left(R_{S T}>F_{\mathrm{ST}}\right)$ was tested with a one-sided permutation test, but significant $(p<0.05)$ contributions of stepwise mutations were only found in maximally three loci in A. millepora (ESM Appendix S9). Therefore, only $F_{\mathrm{ST}}$ and $\mathrm{D}_{\mathrm{EST}}$ were included and compared in the subsequent analyses. The values for $\mathrm{D}_{\mathrm{EST}}$ were slightly higher than for $F_{\mathrm{ST}}$ within Spermonde Archipelago, indicating that $F_{\text {ST }}$ could underestimate the level and pattern of differentiation in these sample sites, especially for site KK. The Mantel test showed no significant correlation between population differentiation (for either $F_{\mathrm{ST}}$ or $\mathrm{D}_{\mathrm{EST}}$ ) and geographic distance between Pulau Seribu and Spermonde Archipelago or within Spermonde Archipelago ( $p>0.05$; ESM Appendix S11 based on transformed $F_{\mathrm{ST}}$ ).

Clustering implemented in STRUCTURE (ESM Appendix $\mathrm{S} 12)$ revealed two clusters $(K=2)$ as the most likely number for all sample sites (Fig. 3c). Based on the proportion of each genetic cluster within each sample site in STRU CTURE, only a shallow structure points to a distinction between Pulau Seribu and Spermonde Archipelago. Within Pulau Seribu, no unambiguous number of clusters was found in STRUCTURE other than $K=2$, in which all sites show mixed signatures (ESM Appendix S12). Within Spermonde Archipelago, two clusters were found in STRUCTU RE (ESM Appendix S13). Based on the proportion of each genetic cluster within each sample site, two groups were distinguished: (1) SL, KK and Ln, and (2) Po, Sa and Ba.

The PCoA shows shallow distinction of Pulau Seribu from Spermonde Archipelago with the third axis generally dividing sites of Pulau Seribu and Spermonde Archipelago, explaining $8 \%$ of the variation (Fig. 5a). In the PCoA based on pairwise $F_{\mathrm{ST}}$ sites in Pulau Seribu and Spermonde Archipelago, together the first axis divides sites SL, KK, Ln from the rest, and the second axis separates KK from this segregation, as well as dividing Po, Sa and $\mathrm{Ba}$, from PA and PS, together explaining $78 \%$ of the variation (Fig. $5 \mathrm{~b}$ ).

The hierarchical AMOVA revealed that 2\% genetic variation was found between clusters within the Java Sea ( $p<0.001$; ESM Appendix S14). No significant grouping was found within Spermonde Archipelago $(p>0.05)$.

\section{Discussion}

This study investigated the genetic diversity and genetic structure of two corals, the brooding coral Seriatopora hystrix and the broadcast spawning coral Acropora millepora at two locations in Indonesia using microsatellite markers. The key indicators used for genetic diversity were the allelic richness and heterozygosity of populations, while genetic structure is determined by the scale of genetic connectivity among populations and depends on the life history of the coral species and oceanographic patterns.

\section{Divergence between Pulau Seribu and Spermonde Archipelago}

Plio-Pleistocene glaciation caused major changes in the marine environment in the Coral Triangle region, with sea levels dropping $120 \mathrm{~m}$ below present during glacial maxima (Voris 2000). However, these environmental changes did not result in uniform patterns of genetic structure of marine organisms, even within functional and taxonomically similar assemblages (Crandall et al. 2008). In this study, a strong signature of divergence associated with historical land barriers at the Sunda Shelf was found for S. hystrix, with one cluster consisting of sample sites in Pulau Seribu, and the other of sites in Spermonde Archipelago confirming hypothesis I. This is consistent with differentiation found for $S$. hystrix (comparing Pulau and Makassar $F_{\mathrm{ST}}=0.19$, Starger et al. (2010)), the coral Heliofungia actiniformis (Knittweis et al. 2009) and a variety of coral reef fauna, such as clownfishes Amphiprion ocellaris and A. perideraion (Timm and Kochzius 2008; Timm et al. 2012; Dohna et al. 2015), stomatopod Haptosquilla pulchella (Barber et al. 2002), Tridacna giant clams (Kochzius and Nuryanto 2008; Nuryanto and Kochzius 2009; Hui et al. 2016; Hui et al. 2017; Keyse et al. 2018), and the sea star Linckia laevigata (Kochzius 


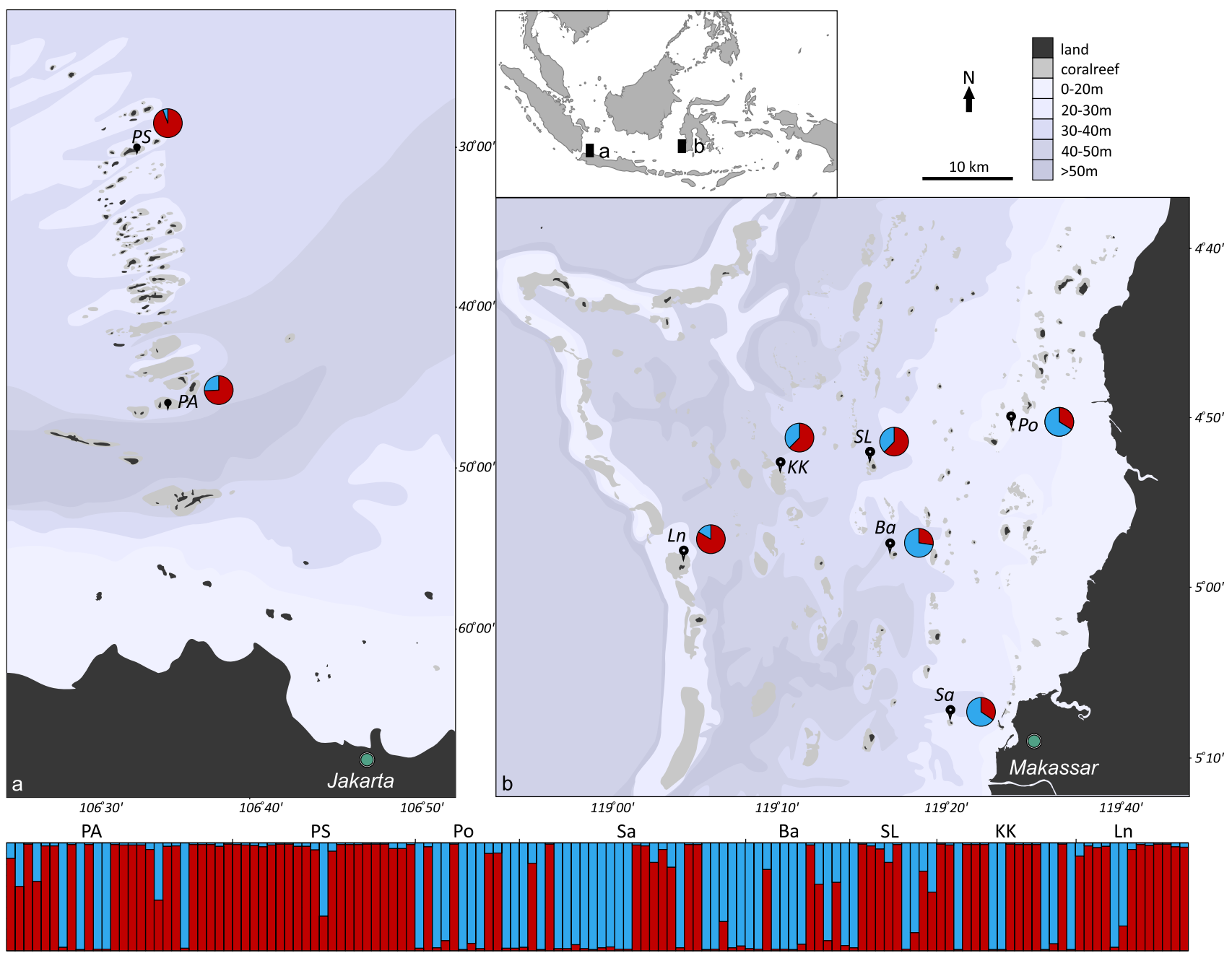

c

Fig. 3 Maps showing sample sites of Acropora millepora in two locations in Indonesia: a Pulau Seribu, and b Spermonde Archipelago. The pie charts show the distribution of the two genetic clusters $(K=2)$ identified by the Bayesian clustering implemented in STRU CTURE 2.3.4 (Pritchard et al. 2000) based on 7 microsatellite loci

et al. 2009; Otwoma and Kochzius 2016), but see Crandall et al. (2019) and the review by Carpenter et al. (2011). This divergence is hypothesised to reflect the historical isolation of ocean basins during the Pliocene and Pleistocene, with subsequent recolonisation after the last glacial maximum. Distance $(>1400 \mathrm{~km})$ as well as contemporary dispersal barriers formed by currents, might play a role in maintaining this divergence, especially for a species with low dispersal capacity such as $S$. hystrix. This is illustrated by the high levels of differentiation that were found in studies on $S$. hystrix covering similar or smaller distances, such as in the Western Indian Ocean (mean $F_{\mathrm{ST}}=0.30-1398 \mathrm{~km}$, van der Ven et al. (2020)) and in the GBR and northern Western Australia (mean $F_{\mathrm{ST}}=0.20-500 \mathrm{~km}$, van Oppen et al. (2008); overall $F_{\mathrm{ST}}=0.198-505 \mathrm{~km}$, Underwood et al. and analysed for all sample sites combined. $\mathbf{c}$ The colours in the bar plot visualise the individual's estimated membership fraction in each of the two clusters, with each vertical bar representing one individual. For sample site codes, see Table 1 and ESM Appendix S1

(2009)). Lower differentiation was found in the Red Sea over a distance of $610 \mathrm{~km},\left(F_{\mathrm{ST}}=0.089\right.$, Maier et al. (2005)), but a lower mean $F_{\mathrm{ST}}$ can be explained by the proximity of most of their sample sites, e.g. $\sim 0.150 \mathrm{~km}$ and a low number of microsatellites (three loci). However, this divergence, of either historical or contemporary barriers, is not pronounced in the broadcast spawning coral A. millepora, for which sample sites in Pulau Seribu and Spermonde Archipelago are only weakly differentiated. This suggests that exchange between these sites does occur, similar to results found in a microsatellite study of the giant clam $T$. crocea (Hui et al. 2017). Acroporids have a high dispersal capacity with a PLD of 59-200 days (Nishikawa et al. 2003; Graham et al. 2008). Low differentiation over long distances was found for congeners A. tenuis in East Africa $\left(F_{\mathrm{ST}}=0.057-900 \mathrm{~km}\right.$, 


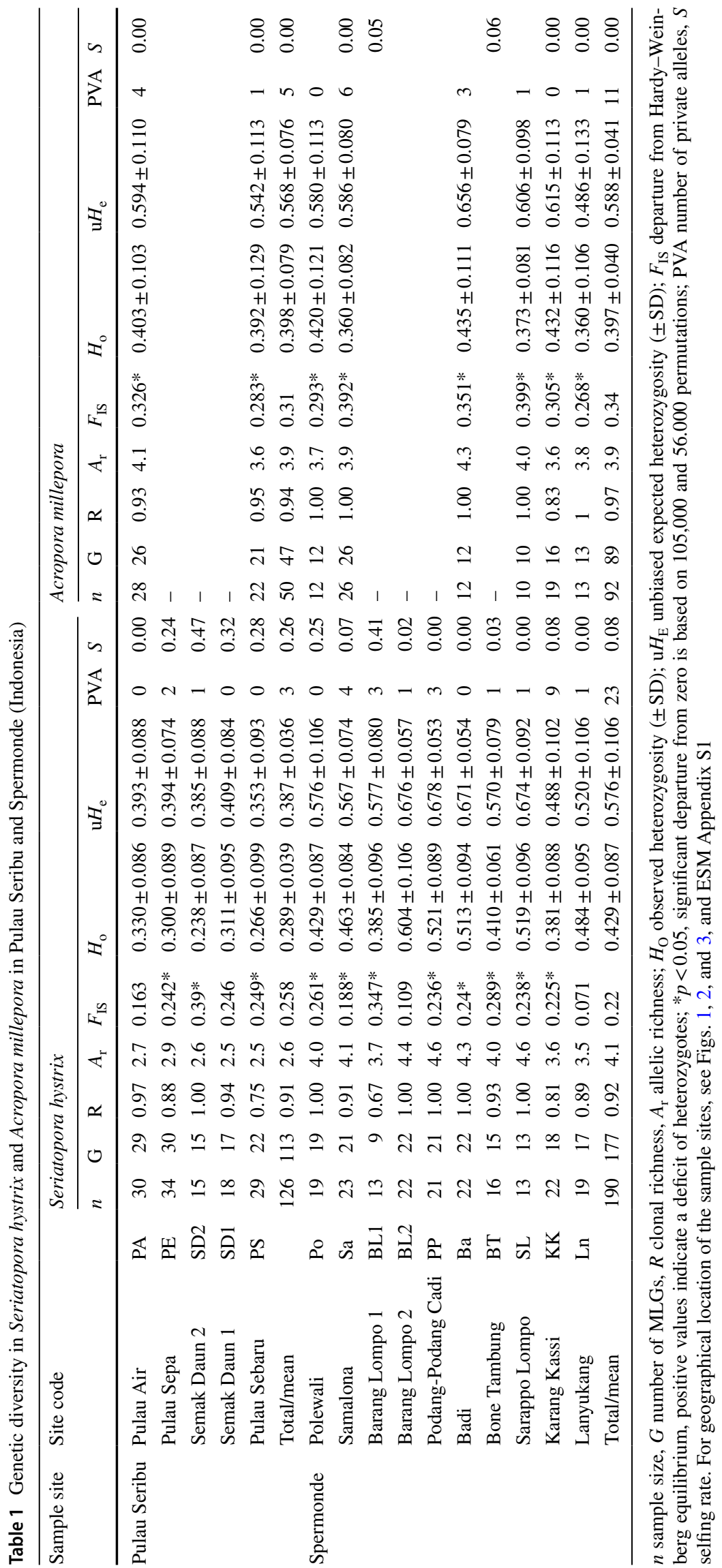


Fig. 4 Principal coordinates analysis (PCoA) conducted with GenAlEx 6.503 (Peakall and Smouse 2012) for Seriatopora hystrix. a Spatial analysis of the genetic distances of all samples from Pulau Seribu (red squares) and Spermonde Archipelago (blue triangles) (Indonesia), the first two axes explain $28 \%$ of the variation (the first axis explains $17 \%$, the second axis explains $11 \%$ of the variation); $\mathbf{b}$ sites in Pulau Seribu based on pairwise $F_{\text {ST }}$ values (Weir and Cockerham 1984), the first two axes explain $91 \%$ of the variation (the first axis explains 66\%, the second axis explains $25 \%$ of the variation); c sites in Spermonde Archipelago based on pairwise $F_{\mathrm{ST}}$ values, the first two axes explain $67 \%$ of the variation (the first axis explains $44 \%$, the second axis explains $23 \%$ of the variation). For sample site codes, see Table 1
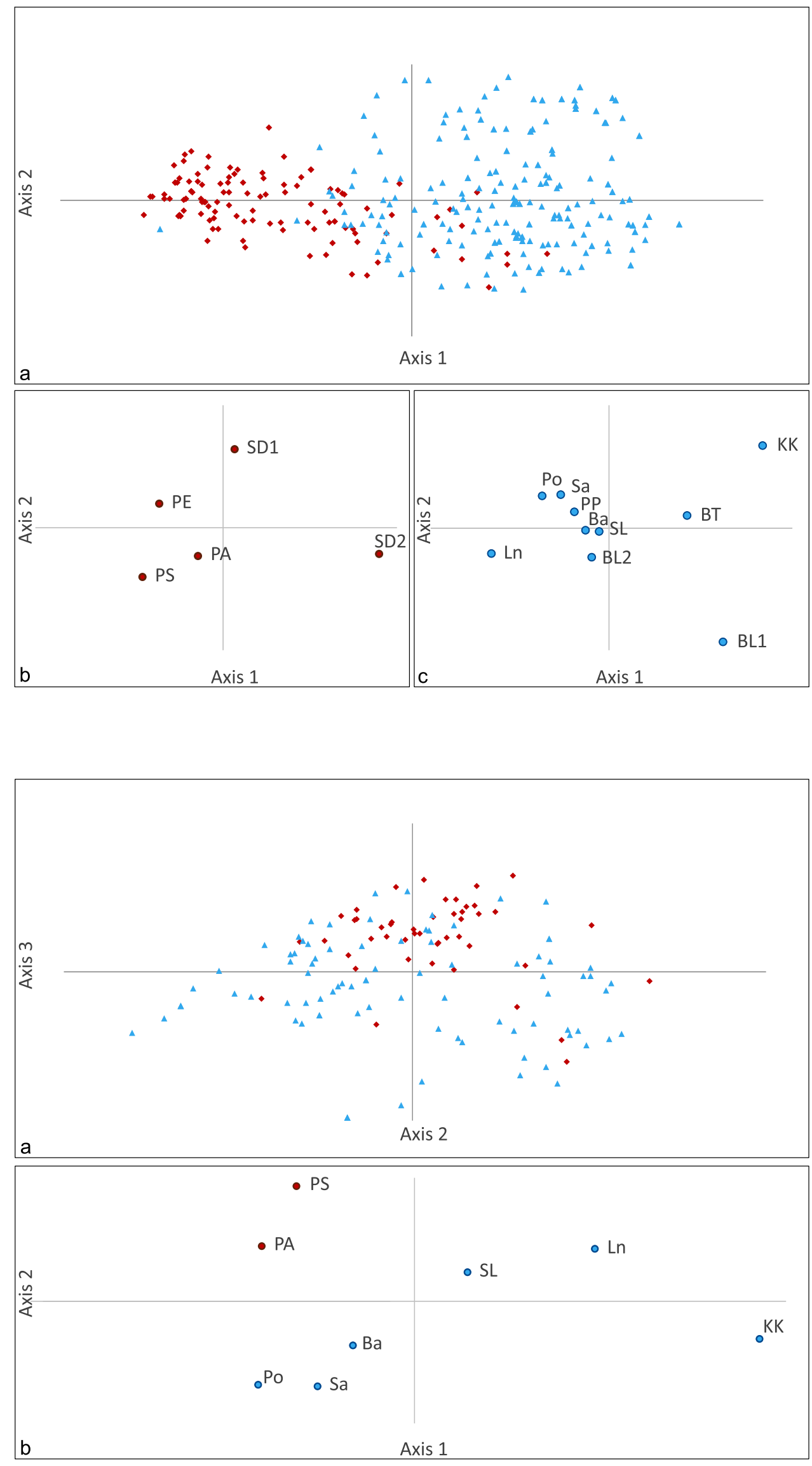

Fig. 5 Principal coordinates analysis (PCoA) conducted with GenAlEx 6.503 (Peakall and Smouse 2012) for Acropora millepora. a Spatial analysis of the genetic distances of all sample sites in Pulau Seribu (red squares) and Spermonde Archipelago (blue triangles) (Indonesia), the second and third axes explain $17 \%$ of the variation (the second axis explains $9 \%$, the third axis explains $8 \%$ of the variation); $\mathbf{b}$ sites in Pulau Seribu and Spermonde Archipelago based on pairwise $F_{\mathrm{ST}}$ values (Weir and Cockerham 1984), the first two axes explain $78 \%$ of the variation (the first axis explains $46 \%$, the second axis explains $32 \%$ of the variation). For sample site codes, see Table 1 
van der Ven et al. (2016) and Acropora digitifera in Japan (pairwise $F_{\mathrm{ST}}<0.034-1000 \mathrm{~km}$, Nakajima et al. (2010)), although higher differentiation was detected for some more offshore sites in A. millepora in the GBR (van Oppen et al. 2011). Furthermore, intermediate populations can function as essential stepping-stones facilitating gene flow in marine populations (Crandall et al. 2012), and several intermediate reefs could potentially form stepping-stones in the Java Sea and Makassar Strait. Even though long-distance dispersal of A. millepora, potentially combined with gene flow through stepping-stones, may have reduced the signal of historic divergence between Pulau Seribu and Spermonde Archipelago, the differentiation between the sites was still found to be significant. Additionally, a two-dimensional stepping stone model could not be confirmed in the Mantel test. Therefore, hypothesis I could not be rejected for A. millepora. Both oceanographic conditions and life history traits likely play an important role, where $S$. hystrix releases larvae yearround, acroporids in Indonesia were found to partake in two synchronised multispecies spawning events per year, one in spring and one in autumn (Keith et al. 2016; Permata et al. 2012; Wijayanti et al. 2019). The prevailing currents during the northeast monsoon (Fig. 1, indicated with the number 2) facilitate spring spawners in Spermonde Archipelago to disperse into the Java Sea, while autumn spawners in the Java Sea are facilitated to disperse towards Spermonde Archipelago by the southwest monsoon (Fig. 1, indicated with the number 1). Brooding corals have the potential for selffertilisation, and (sperm) dispersal also makes outcrossing with related individuals more likely. Both traits contribute to elevated inbreeding levels in marine invertebrates (Olsen et al. 2020). Estimates of selfing for S. hystrix were highly variable but in some populations contributed up to $40 \%$, congruent with selfing rates up to $50 \%$ found on the GBR (Sherman 2008). In contrast, broadcast spawning corals partake in spawning events, with self-fertilisation mostly being restricted (reviewed in Carlon 1999). This was reflected by the low or zero selfing rates for A. millepora in this study. The substantial inbreeding found in some populations of $A$. millepora is, therefore, likely caused by the outcrossing of (closely) related individuals. This is not uncommon as Olsen et al. (2020) showed that many life history traits of sessile marine invertebrates, such as the broadcast spawning of larvae, can lead to population inbreeding. Significantly, lower genetic diversity was found for $S$. hystrix at the sites in Pulau Seribu compared to sites in the Spermonde Archipelago. This was also found for the coral Heliofungia actiniformis (Knittweis et al. 2009) and other coral reef organisms such as the giant clam Tridacna crocea (Kochzius and Nuryanto 2008). One of the explanations for this pattern is the influence of multiple glaciations in the Pliocene and Pleistocene (Voris 2000). Rising sea levels after the last glacial created an opportunity for recolonisation from potentially smaller
Indian Ocean populations. If these new reefs of Pulau Seribu were mainly self-seeding (with minimum immigrants coming in), this could have resulted in a founder effect, with subsequent reduced genetic diversity for $S$. hystrix. Another explanation for the lower genetic diversity in $S$. hystrix from Pulau Seribu is a genetic bottleneck due to the effect of severe reef degradation in the last century (Cleary and Suharsono 2006; Cleary et al. 2014). However, both hypotheses are not supported by the findings for A. millepora, for which the two sites in Pulau Seribu showed no difference in genetic diversity compared to Spermonde Archipelago. This can be explained by the high genetic connectivity found for A. millepora, possibly averting the reduced genetic diversity, although no definite conclusions can be drawn from only two sample sites.

The relative effects of historical and contemporary barriers and life history characteristics cannot be unravelled based on microsatellite markers alone, but it can be concluded that A. millepora is less affected by contemporary barriers currently limiting dispersal of $S$. hystrix between Pulau Seribu and Spermonde Archipelago.

\section{Population structure and genetic diversity within Pulau Seribu}

Genetic differentiation of $S$. hystrix in Pulau Seribu was neither related to geographical distance (isolation by distance) nor associated with zonation, consequently hypothesis II was rejected. Although there was an overall significant differentiation, this was strongly influenced by the substantially higher $F_{\mathrm{ST}}$ found for sites SD1 and SD2, while no differentiation was found for sites $\sim 30 \mathrm{~km}$ apart (PS and $\mathrm{Pa}$ ). High genetic connectivity among sites at relatively small distances is not uncommon for S. hystrix. Similar results of high genetic connectivity for $S$. hystrix populations in the GBR were also found between reefs up to $80 \mathrm{~km}$ apart (van Oppen et al. 2008). There was no indication that the genetic diversity was influenced by an in- to offshore gradient, as there were no differences in genetic diversity within Pulau Seribu for either S. hystrix, or A. millepora. An in- to offshore difference was predicted based on the in- to offshore gradient of anthropogenic stressors around, and to the north of, Jakarta Bay. Jakarta Bay experiences extreme eutrophication coupled with increased primary production, high sedimentation rates and pollution (Rinawati et al. 2012; Baum et al. 2015; Ladwig et al. 2016). However, Jakarta Bay has been subjected to much higher levels of these stressors than mid- to offshore reefs and the effects may be more contained to local reefs within Jakarta Bay itself (Williams et al. 2000). Local anthropogenic stressors, rather than regional southto-north gradients, are, therefore, more likely causing the degradation of reefs in the Pulau Seribu (Baum et al. 2015), 
which could explain the absence of a gradient in the genetic diversity in this study. To get a full picture of the impact of anthropogenic stressors affecting genetic diversity of the corals $S$. hystrix and A. millepora, future research should include more samples from within or close to Jakarta Bay, as well as from midshore locations.

\section{Inshore and offshore structure within Spermonde Archipelago}

The patchy habitat of the 40-km-wide carbonate shelf of Spermonde Archipelago provides the ideal opportunity to study connectivity patterns on a small scale, and to challenge the assumption of panmictic populations. Indeed, significant overall differentiation was found for A. millepora, with low to moderate genetic differentiation between sample sites, as well as significant moderate to high differentiation for the brooding coral $S$. hystrix, confirming hypothesis III. This is congruent with other studies in Spermonde Archipelago, which showed significant division for the coral Heliofungia actiniformis (Knittweis et al. 2009), clownfish Amphiprion ocellaris and ascidian Polycarpa aurata (Timm et al. 2017). Contrary to the study of the coral $H$. actiniformis (Knittweis et al. 2009), there was no indication of isolation by distance for either A. millepora or S. hystrix. However, based on Bayesian cluster analysis, there are groupings of inshore versus more offshore reefs. The first group of A. millepora (Po, $\mathrm{Sa}$, and $\mathrm{Ba}$ ) is highly interconnected with no detectable differentiation among sites. A comparable cluster of sites was found for S. hystrix (Po, Sa, PP, Ba, and SL), characterised by low differentiation, even between sites relatively far apart $(\sim 32 \mathrm{~km})$. These reefs are part of the sheltered inner-shelf and mid-shelf of Spermonde Archipelago, covering shallower reefs down to $40 \mathrm{~m}$ and some between 40 and $50 \mathrm{~m}$. Within this shallower and less exposed environment, these sites are more likely to exchange genetic material within and between local reefs. The second cluster in A. millepora (SL, KK, and Ln) contains mid-shelf and outer-shelf sites and is characterised by higher differentiation. In S. hystrix, KK (far mid-shelf) and Ln (outer shelf) are highly differentiated and form two separate clusters, although KK does show clustering with two differentiated mid-shelf sites (BT and B11) with mixed genotypes. In both A. millepora and $S$. hystrix, the highest level of differentiation was found for the sites KK and Ln, especially when comparing these sites with inner-shelf sites, a pattern also found for a study with the coral $H$. actiniformis (Knittweis et al. 2009). Similarly, cross-shelf genetic structure was found for Acropora nasuta in the Great Barrier Reef over a distance of $<50 \mathrm{~km}$ (Mackenzie et al. 2004). High differentiation in sites located on the far mid-shelf, but especially outer shelf and offshore, can be explained by distance from shore as well as the influence of oceanographic conditions. These sites are more exposed to currents of the ITF, the predominant north to south current in the Makassar Strait, which can facilitate larval input from upstream reefs into the Spermonde Archipelago.

The coral reefs in Spermonde Archipelago were formed under influence of a long-term exposure to an in- to offshore gradient in water quality, and a pattern of species assemblages related to distance from the shore was found for corals, sponges, foraminifera and fish (Cleary et al. 2005; Hoeksema 2012; Polonia et al. 2015; Plass-Johnson et al. 2018). Lower coral species diversity was found closer to shore, while the highest diversity was found in midshore reefs (Cleary et al. 2005). However, this pattern was not found for genetic diversity in corals here, with no significant differences in genetic diversity between the cross-shelf zones for either S. hystrix as A. millepora. This is in congruence with studies on the anemone fish $A$. ocellaris and ascidian, $P$. aurata, in which no differences in genetic diversity based on microsatellite markers were found in a similar study area (Timm et al. 2017). Similar to that study, the lowest diversity values for A. millepora (second lowest for $S$. hystrix), as well as proof of a recent genetic bottleneck for A. millepora were found in Karang Kassi (KK), a site which Timm et al. (2017) argued was heavily impacted by destructive fishing methods. Hardy and Vekemans is in text and in reference list (SPAGeDi (Hardy and Vekemans 2002) was used to test if stepwise mutations added to differentiation (RST $>$ FST), in which case RST (Slatkin 1995) would reflect population differentiation better than FST). Holm too (Statistical significance for all pairwise tests was adjusted for multiple comparisons by a Holm-Bonferroni correction (Holm 1979)).

In conclusion, this study confirms the dispersal barrier between Pulau Seribu and Spermonde Archipelago for $S$. hystrix, while the long-distance dispersal, potentially aided by reefs functioning as stepping stones, was found for $A$. millepora. These contrasting patterns can be explained by differences in life history of these two corals, as well as oceanographic conditions facilitating larval dispersal. The short PLD of the brooding coral $S$. hystrix can result in limited dispersal distances, patterns of high self-recruitment and stronger dispersal barriers, while broadcast spawning corals such as A. millepora share high dispersal potential, with subsequently less defined dispersal barriers. A distinction between inshore versus more differentiated offshore reefs sites was found within Spermonde Archipelago, which can be explained by different oceanographic conditions facilitating larval dispersal. Connectivity data are essential for strategic conservation planning and management. However, substantial differences between connectivity patterns and scale can be expected. Spatial planning of conservation efforts should, therefore, include a wide variety of organisms with different reproduction strategies. 
Acknowledgements We would like to thank the German Federal Ministry of Education and Research (BMBF, Grant no. 03F0643B) for funding; Prof. Dr. D. Blohm (Universität Bremen, Germany) for support and sub-project coordination; Leibniz Centre for Tropical Marine Research (Bremen, Germany) for support, cooperation, and project coordination; A. Neuhaus (Vrije Universiteit Brussel, Belgium), scientists and students of the Hasanuddin University (Makassar, Indonesia) for logistics and help during field work; P. Sutrisno (Vrije Universiteit Brussel, Belgium) for collecting samples; T. Sierens (Vrije Universiteit Brussel, Belgium), T. Demierbe and H. Augustijnen for help in the laboratory; N. van Hoytema (Centre for Environment, Fisheries and Aquaculture Science (Cefas), UK) for proofreading; the competent Indonesian and Belgian authorities for permits. The SPICE project was conducted and permitted under the governmental agreement between the BMBF and the Indonesian Ministry for Research and Technology (RISTEK), Indonesian Institute of Sciences (LIPI), Indonesian Ministry of Maritime Affairs and Fisheries (DKP), and Indonesian Agency for the Assessment and Application of Technology (BPPT). Lastly, we would like to thank the reviewers for their constructive feedback and improvements of the manuscript.

Author contributions MK and RMV conceived the ideas; MK collected the samples; RMV and HH analysed the samples; RMV analysed the data; and RMV led the writing with contributions of all the other authors.

Funding German Federal Ministry of Education and Research (BMBF, Grant no. 03F0643B).

Data availability Sampling locations and microsatellite genotypes are available in the Zenodo Repository (https://doi.org/10.5281/zenodo. 4445180).

\section{Compliance with ethical standards}

Conflict of interest On behalf of all the authors, the corresponding author states that there is no conflict of interest.

Ethical approval All applicable international, national and/or institutional guidelines for sampling, care and experimental use of organisms for the study have been followed and all necessary approvals have been obtained. This study complied with all CITES regulations and the necessary permits (2013BE776/PE, 3260/IV/SATS-LN/2013).

Consent to participate Consent on behalf of all the authors.

Consent for publication Consent on behalf of all the authors.

Open Access This article is licensed under a Creative Commons Attribution 4.0 International License, which permits use, sharing, adaptation, distribution and reproduction in any medium or format, as long as you give appropriate credit to the original author(s) and the source, provide a link to the Creative Commons licence, and indicate if changes were made. The images or other third party material in this article are included in the article's Creative Commons licence, unless indicated otherwise in a credit line to the material. If material is not included in the article's Creative Commons licence and your intended use is not permitted by statutory regulation or exceeds the permitted use, you will need to obtain permission directly from the copyright holder. To view a copy of this licence, visit http://creativecommons.org/licenses/by/4.0/.

\section{References}

Allen GR (2008) Conservation hotspots of biodiversity and endemism for Indo-Pacific coral reef fishes. Aquat Conserv Aquatic 18:541-556

Allen GR, Werner TB (2002) Coral reef fish assessment in the 'coral triangle' of southeastern Asia. Environ Biol Fishes 65:209-214

Almany G, Connolly S, Heath D, Hogan J, Jones G, McCook L, Mills M, Pressey R, Williamson D (2009) Connectivity, biodiversity conservation and the design of marine reserve networks for coral reefs. Coral Reefs 28:339-351

Baird AH (2001) The ecology of coral larvae: settlement patterns, habitat selection and the length of the larval phase. Dissertation, James Cook University

Barber PH, Palumbi SR, Erdmann MV, Moosa MK (2002) Sharp genetic breaks among populations of Haptosquilla pulchella (Stomatopoda) indicate limits to larval transport: patterns, causes, and consequences. Mol Ecol 11:659-674

Baum G, Januar HI, Ferse SCA, Kunzmann A (2015) Local and regional impacts of pollution on coral reefs along the Thousand Islands north of the megacity Jakarta. Indonesia Plos One 10:e0138271

Bellwood DR, Hughes TP, Folke C, Nyström M (2004) Confronting the coral reef crisis. Nature 429:827-833

Besnier F, Glover KA (2013) ParallelStructure: a R package to distribute parallel runs of the population genetics program STRUCTU RE on multi-core Computers. PLoS ONE 8:e70651

Burke L, Reytar K, Spalding M, Perry A (2011) Reefs at risk revisited. World Resources Institute, Washington

Burke L, Reytar K, Spalding M, Perry A (2012) Reefs at risk revisited in the Coral Triangle. World Resources Institute, Washington

Campagne P, Smouse P, Varouchas G, Silvain J, Leru B (2012) Comparing the van Oosterhout and Chybicki-Burczyk methods of estimating null allele frequencies for inbred populations. Mol Ecol Resour 12:975-982

Carlon DB (1999) The evolution of mating systems in tropical reef corals. Trends Ecol Evol 14:491-495

Carpenter KE, Barber PH, Crandall ED, Ablan-Lagman MCA, Ambariyanto, Mahardika GN, Manjaji-Matsumoto BM, JuinioMenez MA, Santos MD, Starger CJ, Toha AHA (2011) Comparative phylogeography of the Coral Triangle and implications for marine management. J Mar Biol 1-14

Chybicki I, Burczyk J (2009) Simultaneous estimation of null alleles and inbreeding coefficients. J Hered 100:106-113

Cleary DFR, Suharsono HBW (2006) Coral diversity across a disturbance gradient in the Pulau Seribu reef complex off Jakarta, Indonesia. Biodivers Conserv 15:3653-3674

Cleary DFR, Becking LE, de Voogd NJ, Renema W, de Beer M, van Soest RWM, Hoeksema BW (2005) Variation in the diversity and composition of benthic taxa as a function of distance offshore, depth and exposure in the Spermonde Archipelago, Indonesia. Estuar Coast Shelf Sci 65:557-570

Cleary DFR, Polonia ARM, Renema W, Hoeksema BW, Wolstenholme J, Tuti Y, de Voogd NJ (2014) Coral reefs next to a major conurbation: a study of temporal change (1985-2011) in coral cover and composition in the reefs of Jakarta, Indonesia. Mar Ecol Prog Ser 501:89-98

Crandall ED, Frey MA, Grosberg RK, Barber PH (2008) Contrasting demographic history and phylogeographical patterns in two IndoPacific gastropods. Mol Ecol 17(2):611-626

Crandall ED, Treml EA, Barber PH (2012) Coalescent and biophysical models of stepping-stone gene flow in neritid snails. Mol Ecol 21(22):5579-5598 
Crandall ED, Riginos C, Bird CE, Liggins L, Treml E, Beger M et al (2019) The molecular biogeography of the Indo-Pacific: testing hypotheses with multispecies genetic patterns. Glob Ecol Biogeogr 58(5):403-418

David P, Pujol B, Viard F, Castella V, Goudet J (2007) Reliable selfing rate estimates from imperfect population genetic data. Mol Ecol 16(12):2474-2487

Dohna TA, Timm J, Hamid L, Kochzius M (2015) Limited connectivity and a phylogeographic break characterize populations of the pink anemonefish, Amphiprion perideraion, in the Indo-Malay Archipelago: inferences from a mitochondrial and microsatellite loci. Ecol Evol 5:1717-1733

Earl D, Vonholdt B (2012) STRUCTURE HARVESTER: a website and program for visualizing STRUCTURE output and implementing the Evanno method. Conserv Genet Resour 4:359-361

Edinger EN, Jompa J, Limmon GV, Widjatmoko W, Risk MJ (1998) Reef degradation and coral biodiversity in Indonesia: effects of land-based pollution, destructive fishing practices and changes over time. Mar Pollut Bull 36:617-630

Edinger EN, Copper SP, Risk MJ, Atmojo W (2002) Oceanography and reefs of recent and Paleozoic tropical epeiric seas. Facies 47:127-149

Evanno G, Regnaut S, Goudet J (2005) Detecting the number of clusters of individuals using the software STRUCTURE: a simulation study. Mol Ecol 14:2611-2620

Excoffier L, Smouse PE, Quattro JM (1992) Analysis of molecular variance inferred from metric distances among DNA haplotypes: application to human mitochondrial DNA restriction data. Genetics 131:479-491

Foale S, Adhuri D, Alino P, Allison EH, Andrew N, Cohen P, Evans L, Fabinyi M, Fidelman P, Gregory C, Stacey N, Tanzer J, Weeratunge N (2013) Food security and the coral triangle initiative. Mar Policy 38:174-183

Gordon A (2005) Oceanography of the Indonesian Seas and their throughflow. Oceanogr 18:14-27

Goudet J (1995) FSTAT (Version 1.2): a computer program to calculate F-statistics. J Hered 86:485-486

Graham EM, Baird AH, Connolly SR (2008) Survival dynamics of scleractinian coral larvae and implications for dispersal. Coral Reefs 27:529-539

Green AL, Fernandes L, Almany G, Abesamis R, McLeod E, Alino PM, White AT, Salm R, Tanzer J, Pressey RL (2014) Designing marine reserves for fisheries management, biodiversity conservation, and climate change adaptation. Coast Manage 42:143-159

Hardy OJ, Vekemans X (2002) SPAGEDi: a versatile computer program to analyse spatial genetic structure at the individual or population levels. Mol Ecol Notes 2(4):618-620

Hardy OJ, Charbonnel N, Freville H, Heuertz M (2003) Microsatellite allele sizes: a simple test to assess their significance on genetic differentiation. Genetics 163(4):1467-1482

Hoegh-Guldberg O, Poloczanska ES, Skirving W, Dove S (2017) Coral reef ecosystems under climate change and ocean acidification. Front Mar Sci 4:158

Hoeksema BW (2012) Distribution patterns of mushroom corals (Scleractinia: Fungiidae) across the Spermonde shelf, south Sulawesi. Raffles Bull Zool 60:183-212

Holm S (1979) A simple sequentially rejective multiple test procedure. Scand J Stat 6:65-70

Hui M, Kraemer WE, Seidel C, Nuryanto A, Joshi A, Kochzius M (2016) Comparative genetic population structure of three endangered giant clams (Cardiidae: Tridacna species) throughout the Indo-West Pacific: implications for divergence, connectivity and conservation. J Molluscan Stud 82:403-414

Hui M, Nuryanto A, Kochzius M (2017) Concordance of microsatellite and mitochondrial DNA markers in detecting genetic population structure in the boring giant clam Tridacna crocea across the IndoMalay Archipelago. Mar Ecol-Evol Persp 38:e12389

Jost L (2008) $\mathrm{G}_{\mathrm{ST}}$ and its relatives do not measure differentiation. Mol Ecol 17:4015-4026

Jost L, Archer F, Flanagan S, Gaggiotti O, Hoban S, Latch E (2018) Differentiation measures for conservation genetics. Evol Appl 11:1139-1148

Keith SA, Maynard JA, Edwards AJ, Guest JR, Bauman AG, Van Hooidonk R, Heron SF, Berumen ML, Bouwmeester J, Piromvaragorn S, Rahbek C (2016) Coral mass spawning predicted by rapid seasonal rise in ocean temperature. Proc R Soc B 283(1830):20160011

Keyse J, Treml EA, Huelsken T, Barber PH, DeBoer T, Kochzius M, Nuryanto A, Gardner JPA, Liu LL, Penny S, Riginos C (2018) Historical divergences associated with intermittent land bridges overshadow isolation by larval dispersal in co-distributed species of Tridacna giant clams. J Biogeogr 45:848-858

Knittweis L, Kraemer WE, Timm J, Kochzius M (2009) Genetic structure of Heliofungia actiniformis (Scleractinia: Fungiidae) populations in the Indo-Malay Archipelago: implications for live coral trade management efforts. Conserv Genet 10:241-249

Kochzius M, Nuryanto A (2008) Strong genetic population structure in the boring giant clam, Tridacna crocea, across the Indo-Malay Archipelago: implications related to evolutionary processes and connectivity. Mol Ecol 17:3775-3787

Kochzius M, Seidel C, Hauschild J, Kirchhoff S, Mester P, MeyerWachsmuth I, Nuryanto A, Timm J (2009) Genetic population structures of the blue starfish Linckia laevigata and its gastropod ectoparasite Thyca crystallina. Mar Ecol Prog Ser 396:211-219

Ladwig N, Hesse KJ, van der Wulp SA, Damar A, Koch D (2016) Pressure on oxygen levels of Jakarta Bay. Mar Pollut Bull 110:665-674

Mackenzie JB, Munday PL, Willis BL, Miller DJ, van Oppen MJH (2004) Unexpected patterns of genetic structuring among locations but not colour morphs in Acropora nasuta (Cnidaria; Scleractinia). Mol Ecol 13:9-20

Maier E, Tollrian R, Rinkevich B, Nurnberger B (2005) Isolation by distance in the scleractinian coral Seriatopora hystrix from the Red Sea. Mar Biol 147:1109-1120

Meirmans PG, Hedrick PW (2011) Assessing population structure: $F_{\mathrm{ST}}$ and related measures. Mol Ecol Resour 11(1):5-18

Miller MA, Schwartz T, Pickett BE, He S, Klem EB, Scheuermann RH, Passarotti M, Kaufman S, O'Leary MA (2015) A RESTful API for access to phylogenetic tools via the CIPRES science gateway. Evol Bioinform 11:43-48

Nakajima Y, Nishikawa A, Iguchi A, Sakai K (2010) Gene flow and genetic diversity of a broadcast-spawning coral in northern peripheral populations. PLoS ONE 5:e11149

Nishikawa A, Katoh M, Sakai K (2003) Larval settlement rates and gene flow of broadcast-spawning (Acropora tenuis) and planula-brooding (Stylophora pistillata) corals. Mar Ecol Prog Ser 256:87-97

Nuryanto A, Kochzius M (2009) Highly restricted gene flow and deep evolutionary lineages in the giant clam Tridacna maxima. Coral Reefs 28:607-619

Olsen KC, Ryan WH, Winn AA, Kosman ET, Moscoso JA, KruegerHadfield SA, Burgess SC, Carlon DB, Grosberg RK, Kalisz S, Levitan DR (2020) Inbreeding shapes the evolution of marine invertebrates. Evol 74-5:871-882

Otwoma LM, Kochzius M (2016) Genetic population structure of the coral reef sea star Linckia laevigata in the Western Indian Ocean and Indo-West Pacific. PLoS ONE 11:e0165552

Peakall R, Smouse P (2012) GenAlEx 6.5: genetic analysis in Excel. Population genetic software for teaching and research-an update. Bioinformatics 28:2537-2539 
Permata D, Indrayanti E, Haryanti D, Fika L, Arfiyan H, Achmad A (2012) Biannual multispecific spawning in Karimunjawa Archipelago, Indonesia. Coral Reefs 31(3):907

Plass-Johnson JG, Teichberg M, Bednarz VN, Gärdes A, Heiden JP, Lukman M, Miñarro S, Kegler H, Weiand L, Wild C, Reuter $\mathrm{H}$, Ferse SCA (2018) Spatio-temporal patterns in the coral reef communities of the Spermonde Archipelago, 2012-2014, II: fish assemblages display structured variation related to benthic condition. Front Mar Sci 5:36

Polonia ARM, Cleary DFR, de Voogd NJ, Renema W, Hoeksema BW, Martins A, Gomes NCM (2015) Habitat and water quality variables as predictors of community composition in an Indonesian coral reef: a multi-taxon study in the Spermonde Archipelago. Sci Total Environ 537:139-151

Prasetia R, Sinniger F, Hashizume K, Harii S (2017) Reproductive biology of the deep brooding coral Seriatopora hystrix: implications for shallow reef recovery. PLoS One 12(5):e0177034

Pritchard J, Stephens M, Donnelly P (2000) Inference of population structure using multilocus genotype data. Genetics 155:945-959

Rinawati KT, Koike H, Kurumisawa R, Ito M, Sakurai S, Togo A, Saha M, Arifin Z, Takada H (2012) Distribution, source identification, and historical trends of organic micropollutants in coastal sediment in Jakarta Bay, Indonesia. J Hazar Mater 217:208-216

Rousset F (1997) Genetic differentiation and estimation of gene flow from F-statistics under isolation by distance. Genetics 145(4):1219-1228

Sherman, CDH (2008) Mating system variation in the hermaphroditic brooding coral, Seriatopora hystrix. Heredity 100(3):296-303

Slatkin M (1995) A measure of population subdivision based on microsatellite allele frequencies. Genetics 139(1):457-462

Starger CJ, Barber PH, Ambariyanto BAC (2010) The recovery of coral genetic diversity in the Sunda Strait following the 1883 eruption of Krakatau. Coral Reefs 29:547-565

Timm J, Kochzius M (2008) Geological history and oceanography of the Indo-Malay Archipelago shape the genetic population structure in the false clown anemonefish (Amphiprion ocellaris). Mol Ecol 17:3999-4014

Timm J, Planes S, Kochzius M (2012) High similarity of genetic population structure in the false clown anemonefish (Amphiprion ocellaris) found in microsatellite and mitochondrial control region analysis. Conserv Genet 13:693-706

Timm J, Kochzius M, Madduppa HH, Neuhaus AI, Dohna T (2017) Small scale genetic population structure of coral reef organisms in Spermonde Archipelago, Indonesia. Front Mar Sci 4

Underwood JN, Smith LD, van Oppen MJH, Gilmour JP (2007) Multiple scales of genetic connectivity in a brooding coral on isolated reefs following catastrophic bleaching. Mol Ecol 16:771-784
Underwood JN, Smith LD, van Oppen MJH, Gilmour JP (2009) Ecologically relevant dispersal of corals on isolated reefs: implications for managing resilience. Ecol Appl 19:18-29

van Oosterhout C, Hutchinson WF, Wills DPM, Shipley P (2004) MICRO-CHECKER: software for identifying and correcting genotyping errors in microsatellite data. Mol Ecol Notes 4:535-538

van Oppen MJH, Lutz A, De'ath G, Peplow L, Kininmonth S (2008) Genetic traces of recent long-distance dispersal in a predominantly self-recruiting coral. PLoS ONE 3:e3401

van Oppen MJH, Peplow LM, Kininmonth S, Berkelmans R (2011) Historical and contemporary factors shape the population genetic structure of the broadcast spawning coral, Acropora millepora, on the Great Barrier Reef. Mol Ecol 20:4899-4914

van der Ven RM, Triest L, De Ryck DJR, Mwaura JM, Mohammed MS, Kochzius M (2016) Population genetic structure of the stony coral Acropora tenuis shows high but variable connectivity in East Africa. J Biogeogr 43:510-519

van der Ven RM, Flot JF, Buitrago-López C, Kochzius M (2020). Population genetics of the brooding coral Seriatopora hystrix reveals patterns of strong genetic differentiation in the Western Indian Ocean. Heredity $1-15$

Veron JEN (2000) Corals of the world. Australian Institute of Marine science, Townsville

Veron JEN, Devantier LM, Turak E, Green AL, Kininmonth S, Stafford SM, Peterson N (2009) Delineating the coral triangle. Galaxea 11:91-100

Voris HK (2000) Maps of Pleistocene sea levels in Southeast Asia: shorelines, river systems and time durations. J Biogeogr 27:1153-1167

Waits LP, Luikart G, Taberlet P (2001) Estimating the probability of identity among genotypes in natural populations: cautions and guidelines. Mol Ecol 10:249-256

Weir BS, Cockerham CC (1984) Estimating F-statistics for the analysis of population-structure. Evolution 38:1358-1370

Wijayanti DP, Indrayanti E, Wirasatriya A, Haryanto A, Haryanti D, Sembiring A, Fajrianzah TA, Bhagooli R (2019) Reproductive seasonality of coral assemblages in the Karimunjawa Archipelago, Indonesia. Front Mar Sci 6:195

Williams TM, Rees JG, Setiapermana D (2000) Metals and trace organic compounds in sediments and waters of Jakarta Bay and the Pulau Seribu complex, Indonesia. Mar Pollut Bull 40:277-285

Wyrtki K (1961) Physical oceanography of the Southeast Asian waters. NAGA Report Vol. 2, The University of California, Scripps Institution of Oceanography, La Jolla

Publisher's Note Springer Nature remains neutral with regard to jurisdictional claims in published maps and institutional affiliations. 